\title{
Ensaios
}

\author{
Jonatas Ferreira
}

Universidade Federal de Pernambuco

\author{
Cynthia Hamlin
}

Universidade Federal de Pernambuco

\section{Mulheres, negros e outros monstros: um ensaio sobre corpos não civilizados}

\begin{abstract}
Resumo: A dinâmica ocidental de civilização implica uma relação tensa entre corpo e mente, cultura e natureza, civilização e barbarismo. No ensaio que se segue, exploramos a construção deste último dualismo ao investigarmos os espaços nos quais certos corpos são definidos como monstruosos. Em particular, estamos interessados na constituição de uma visão científica de diferenças raciais, sua especificidade em relação à percepção medieval do lugar da alteridade, seu papel em legitimar a circulação de corpos 'monstruosos' como mercadorias e sua reivindicação de desvendar uma hierarquia objetiva de raças e gênero. De Lavater a Curvier, a classificação das espécies oferece um modelo hierárquico que será apropriado pelos discursos de raça e gênero na biologia. Nesse contexto, um caso pode ser considerado paradigmático: a 'Vênus Hotentote'. Argumentamos que a negociação política do status ontológico de Sara Baartman, durante os séculos XIX e XX, representa precisamente tal esforço para estabelecer as fronteiras de civilidade mediante a circulação e a exclusão de corpos incivilizados.
\end{abstract}

Palavras-Chave: mulheres; corpos negros; teratologia; ciência.

Copyright (C) 2010 by Revista Estudos Feministas.
"O basilisco [monstro em forma de serpente] é capaz de fulminar o homem pelo olhar porque, ao vê-lo [...] põe em movimento pelo corpo um terrível veneno que, lançado pelos olhos, impregna a atmosfera com sua substância mortífera [...] Mas quando é o homem que vai ao encontro da fera guarnecido de espelhos [...] o resultado é diverso: o monstro, vendo-se refletido nos espelhos, lança seu veneno contra o seu próprio reflexo: 0 veneno é repelido, retorna sobre ele e o mata." (Malleus Maleficarum: o martelo das feiticeiras - Heinrich KRAMER e James SPRENGER, 1991, p. 73)

\section{Introdução}

Na história do pensamento ocidental, mulheres, negros e monstros têm algo em comum: uma suposta proximidade 


\footnotetext{
${ }^{1}$ Sempre que utilizarmos o termo "homem" estamos nos referindo ao Homem Universal do ocidente, cujas raízes se encontram no pensamento grego.
}

com a natureza que configura a essência liminar de sua humanidade. Segundo tal forma de pensar, um espaço de civilização que se contraponha a essa proximidade deve ser forjado - um espaço em que, da segurança do mundo da cultura, seja possível objetivar e controlar esses seres fronteiriços. De fato, a constituição de um discurso civilizador abre-se em oposições fundamentadas na identificação de um hiato entre natureza e cultura: corpo versus mente, prazer versus razão, forma versus essência, matéria versus ideia etc. Assim, é comum que o discurso civilizador constitua as seguintes alternativas polares: a natureza alimenta, nutre e constitui nosso lugar dentro da existência; ao mesmo tempo, corrompe essa existência, sepulta-a, impõe-se ao homem ${ }^{1}$ civilizado como poder incontrolável, caótico, apavorante. A natureza é simultaneamente fecundidade e luto.

É importante considerar que o discurso civilizador não se estrutura exclusivamente em um dos polos dessa oposição, mas na arquitetura que coloca tais alternativas como algo inquestionável. Na prática, porém, tal discurso precisa excluir incluindo e incluir o outro sob o estigma da exclusão. É, portanto, da própria ambiguidade que deriva sua força, embora, paradoxalmente, seja tanto mais forte quanto menos ambíguo se mostre. É a constituição desses lugares que será investigado aqui. Em linhas gerais, nosso propósito é demonstrar como a ambiguidade diante da alteridade foi objeto de negociações distintas ao longo da história do Ocidente. Em particular, interessa-nos o modo como a constituição da sociedade moderna e de um discurso científico resultou em imagens monstruosas de alteridade, na produção discursiva de corpos considerados exóticos e, no limite, abjetos.

Inicialmente, consideraremos os elementos ambíguos que marcaram as representações culturais da mulher e do negro e que possibilitam sua caracterização como um/a Outro/ a monstruoso/a. Argumentaremos que o monstruoso aparece como o lugar da alteridade por excelência, um lugar que marca a fronteira entre criação e corrupção, ordem e caos, civilização e barbárie. Na sociedade medieval, em que a circulação dos corpos era restrita pela sua própria lógica econômica (o mercado tinha uma importância restrita, local), o monstruoso sempre esteve associado à ideia de circulação imprópria. Numa sociedade que se moderniza, a partir do comércio, da circulação de corpos e mercadorias, uma outra lógica civilizadora teve que ser concebida. Nesse sentido, argumentamos que o surgimento de um sistema de classificação taxonômico representou um primeiro passo legitimador do aumento da circulação de corpos e objetos transformados em mercadoria com o processo de expansão capitalista. Esse sistema de classificação, que constitui a base 
2 FOUCAULT, 1987.

${ }^{3}$ Correspondendo ao ingresso das ciências da vida no processo de legitimação e viabilização de um espaço moderno de poder, essa transição é um tema recorrente na obra de Michel Foucault. Textos como Eu Pierre Rivière, que estrangulei minha mãe, minha irmã e meu irmão; Vigiar e punir e algumas de suas aulas publicadas em Em defesa da sociedade indicam a persistência desse interesse ao longo da obra de Foucault. da ciência moderna, representa uma ruptura. Para usarmos uma distinção semelhante àquela que Michel Foucault ${ }^{2}$ faz com respeito à loucura, diríamos que o monstruoso deixa de ser concebido, primordialmente, como objeto de julgamento moral e passa a ser explicado pela biologia. ${ }^{3}$ Distintamente do argumento foucaultiano, acreditamos que o elemento moralizante continuou claramente vivo, subjacente à explicação científica. Essa nova concepção do monstruoso, na exata medida em que se pretende científica, busca ocultar sua matriz valorativa, concebendo esses seres como espécimes naturais. A suposta isenção daquilo que se considera 'natural' é o ponto a partir do qual se essencializa uma explicação histórica e política. Tal naturalização é o equivalente moderno do ritual de exorcismo descrito no Martelo das feiticeiras: ao promover hierarquias raciais e de gênero e localizar o/a Outro/a do civilizado na base dessas hierarquias, a reflexão científica busca, ao mesmo tempo, neutralizar seus poderes, funcionando como o espelho que reflete a mirada do monstro sobre si mesmo. É justamente quando se percebe que esse olhar não é axiologicamente neutro que esse/a Outro/a monstruoso/a surge como um problema real cuja emergência e efeitos precisam ser explicados.

A fim de ilustrar nossos argumentos, efetuaremos um estudo de caso referente a Sara Baartman, mais conhecida como Vênus Hotentote. Baartman nos interessa porque representa uma convergência importante entre os principais pontos levantados aqui. Em primeiro lugar, além de mulher, é negra. Em segundo lugar, representa um caso extremo de constituição de identidade a partir do olhar do outro. Privada de sua própria voz e da perspectiva cultural de seu povo, sua identidade pessoal foi inteiramente subsumida à sua identidade social, fazendo dela uma espécie de significante vazio que reflete os valores dos grupos que a constituem como um tipo específico de sujeito. Por fim, ao ser submetida a três tipos de olhares distintos - a selvagem perigosa e amoral; o negro como raça biologicamente distinta e a heroína dos modernos movimentos sociais - a circulação de seu corpo, desde o século XIX, tem garantido a manutenção da lógica civilizatória europeia.

\section{Corpos femininos, corpos negros, corpos ambíguos}

Não é fortuito que algumas imagens culturais da mulher e do negro estejam ligadas à ideia de natureza como fecundidade e como luto. Por um lado, a mulher é vista como mãe santificada, mãe puríssima, caminho para a salvação. Seu corpo pode estar associado à fertilidade, à 
${ }^{4}$ Ver a esse respeito, por exemplo, Catherine BLACKLEDGE, 2003, p. 29-33 e George MINOIS, 2003. Mary DEL PRIORE, 1993 também nos fala de algumas gravuras medievais em que o Diabo é expulso de determinados ambientes pela exibição da genitália feminina-esse ato é encontrado, de resto, em diversas culturas como parte de rituais de fecundidade ou de exorcismo de maus espíritos.

${ }^{5}$ Félix GUIRAND, 1935.

${ }^{6}$ DELUMEAU, 1999, p. 312. fecundidade, à virtude de possuir qualidades apotropaicas, isto é, capazes de afastar malefícios e desgraças. Esse é o caso, por exemplo, das Sheelas-na-Gig, imagens femininas esculpidas em igrejas e castelos medievais do Reino Unido e França, dotadas de certas qualidades mágicas, como promover a fecundidade e evitar a aproximação de maus espíritos mediante a exibição de suas genitálias. ${ }^{4}$ Ao mesmo tempo, a mulher é percebida como puta, agente do demônio, noturna, caminho para a perdição, 'vagina dentada', ausência de pênis. O corpo feminino é objeto de uma ansiedade fundamental e exemplos desse fenômeno são abundantes em várias culturas. Na Grécia clássica, Ulisses não teve de se defrontar com os encantos terríveis de Cila e de Caríbdis? Descrevendo a Roma de Nero, Petrônio, em Satiricon, não opôs os ternos cuidados maternos ao poder medonho de bruxas capazes de transformar com seu toque nefasto homens sãos em moribundos, crianças ternas em bonecos de palha?

Interessa-nos aqui não essas visões em sua parcialidade, mas a produtividade de sua ambiguidade, uma produtividade que se manifesta num misto de desejo, repulsa e necessidade de controle. E poucas representações do feminino encarnam essa ambiguidade de forma mais evidente do que a Vênus (Afrodite, para os gregos). A riqueza da imagem de Afrodite reside em suas representações múltiplas do feminino. Em sua origem, era uma deusa da fertilidade e sua ação se estendia a toda a natureza, plantas, animais e seres humanos. Em seguida, torna-se a deusa do amor, de suas formas mais nobres às mais degradantes. A Afrodite Urânia (ou Celeste) representa o amor puro, ideal; a Afrodite Genetriz (ou Nínfia) presidia os partos; a Afrodite Hetaíra (ou Porné, ou Pandemós) era a deusa da lubricidade, do amor venal, patronesse das prostitutas. ${ }^{5}$ Nas palavras de Jean Delumeau:

Essa ambiguidade fundamental da mulher que dá a vida e anuncia a morte foi sentida ao longo dos séculos, e especialmente expressa pelo culto das deusas-mães. A terra é o ventre nutridor, mas também o reino dos mortos sob o solo ou na água profunda. É cálice de vida e de morte. ${ }^{6}$

Com o negro ocorre algo semelhante. Se é comum encontrarmos discursos nos quais ele é apresentado como bom selvagem, força da natureza, alma dócil, pacífica, objeto de desejo, ele é, ao mesmo tempo, desregrado, macaco, lugar de vício, luxúria, repulsa. A docilidade e a intriga, por exemplo, amalgamam-se na descrição do caráter do africano que nos pinta Gilberto Freyre em Casa Grande e Senzala. De modo semelhante, o suicídio da negra Bertoleza, no Cortiço, 
${ }^{7}$ BHABHA, 1998, p. 105.

${ }^{8}$ Richard SENNETT, 2003, p. 31. de Aluísio Azevedo, é traduzido como a voz da natureza acuada, caos de sangue e tripas, escamas de peixe, a confirmação da legitimidade de sua condição subalterna, e, ao mesmo tempo, a negação radical dessa condição. Positiva ou negativamente avaliada, a proximidade que existiria entre negros, mulheres e a natureza é o que importa aqui. É a produção discursiva dessa proximidade que será objeto de desejo de controle e de ansiedade. Como lembra Homi Bhabha, a força ambígua do estereótipo, representada sobretudo pela necessidade de civilização e impossibilidade de civilização, merece nesses casos uma apreciação cuidadosa, já que

o estereótipo, que é sua [do discurso colonial] principal estratégia discursiva, é uma forma de conhecimento e identificação que vacila entre o que está "no lugar", já conhecido, e algo que deve ser ansiosamente repetido... como se a duplicidade essencial do asiático ou a bestial liberdade sexual do africano, que não precisam de prova, não pudessem na verdade jamais ser provadas no discurso.?

A ideia civilizadora no Ocidente implicou uma concepção idealizada do corpo e uma delimitação de espaços específicos de civilidade. Assim, o calor civilizado do corpo do jovem ateniense e a ágora complementam-se; um é extensão do outro. Para o ateniense bem-nascido, a "nudez simboliza um povo inteiramente à vontade na sua cidade, expostos e felizes, ao contrário dos bárbaros, que vagavam [cobertos] sem objetivo e sem a proteção da pedra". ${ }^{8}$ O corpo atlético do jovem guerreiro ateniense, símbolo de sua areté, situado dentro dos limites protetores da cidade, é capaz de desafiar a natureza. O homem grego busca exibir seu corpo como sinal pleno de distinção: o nu do atleta grego não é apenas uma ostentação cosmética, mas expressão de civilidade desse corpo. Em contraposição a isso, interessa-nos a frieza, a obscuridade, a lascívia como marcas de falta de civilidade dos corpos negros, femininos, monstruosos; interessa-nos os lugares ermos que eles ocupam.

Como mulher, negro ou monstro, o outro é aquilo que em princípio não deve circular, mas também aquilo que não pode deixar de circular, sob pena de privar o discurso civilizador da oposição que o funda: em sua feiura, desproporção, desordem, o monstro é o outro do civilizado. A estruturação de um discurso civilizador se opera no concreto dos corpos e nos caminhos traçados para a sua circulação. Civilizar significa aprender como os corpos devem trafegar e indicar esses caminhos - e por esse motivo o discurso civilizador não pode deixar de ser ambíguo, revelando um ocultamento fundamental: a possibilidade do retorno do 
9 Martin JAY, 1994, em Downcast Eyes, de uma perspectiva crítica, oferece uma excelente análise do 'anti-ocularcentrismo' que marca o pensamento francês do século $\mathrm{XX}$. olhar da natureza, da mulher, do negro, do monstro. Retorno que reflete a mirada civilizadora sobre si e que revela sua ansiedade essencial.

\section{O monstruoso: visibilidade e trânsito}

A epígrafe que abre este ensaio sintetiza alguns motivos pelos quais elegemos o corpo monstruoso como imagem que sintetiza algumas de nossas preocupações teóricas. Primeiro, o conteúdo misógino do Malleus Maleficaram, manual da Inquisição que levou à perseguição e à morte mais de 100 mil mulheres em quatro séculos, é aqui apresentando nos termos de uma relação entre ver e ser visto; entre controlar e ser controlado pelo olhar; entre a possibilidade do domínio de homens ou de monstros; entre tornar alguém objeto ou tornar-se objeto deste alguém. Ver, nesse contexto, significa a possibilidade de controlar. Ser visto significa a iminência de ser destruído - pois tornar-se objeto e ser destruído aqui significam a mesma coisa.

A esse tipo de conclusão chega com frequência o pensamento francês. Sartre, Bataille, Foucault, em particular, mostraram-se bastante sensíveis em relação ao poder do olhar no ocidente, com a cumplicidade íntima que existe entre filosofar, teorizar e fixar o outro no pensamento. ${ }^{9}$ Mais que qualquer outro sentido, a visão é o sentido da objetivação, o sentido capaz de promover uma separação entre sujeito e objeto: vejo aquilo sobre o qual ganho perspectiva, distância. Debrucemo-nos um pouco mais sobre - Malleus Maleficarum. Existem miradas capazes de nos paralisar, de exercer controle sobre nossos espíritos - e os aniquilar como tais. Por esse motivo, receitam-se algumas precauções: contra o poder do olhar do Outro, da Outra, o espelho, o ardil, a tortura, a fogueira. A mirada do monstro, da bruxa, envenena a atmosfera, atuando como veículo de forças demoníacas, coléricas, caóticas. Lembremos que a moderna ótica ainda não se instalara: o olho não é apenas uma tela que recebe os raios de luz rebatidos pelos objetos; o olhar projeta sua luz. Se o/a Outro/a me vê, se ele/a me torna objeto de sua mirada, dilui-me enquanto sujeito, desfaz-me enquanto instância primordial que antecede ontologicamente o seu existir. Se o/a Outro/a é capaz de me 'objetificar', é possível que haja ali uma reivindicação de civilidade tão ou mais legítima que a minha.

Posto que a suspeita da legitimidade da mirada do/ a Outro/a não pode ser superada, ela precisa ser recorrentemente reprimida. É preciso afirmar que o monstro é caos formal, é carência de um princípio ordenador no concreto de seu corpo. Enquanto tal, a monstruosidade não constitui ameaça de um novo poder civilizador, mas o risco 
10 Heinrich KRAMER e James SPRENGER, 1991. de que toda civilidade pereça. De acordo com Kramer e Sprenger, ${ }^{10}$ o demônio não possui força criativa; seu poder corruptor está em, com a permissão de Deus, misturar de modo nocivo elementos já existentes no mundo. Assim, é possível dizer que o demônio é pura entropia. Sua força reside em retirar tais elementos de seu lugar próprio, combinando-os de modo caótico, monstruoso. A ação do demônio evoca necessariamente questões de pertencimento e de circulação, de trânsito de lugares adequados para lugares inadequados.

Nesses termos, insinua-se no Malleus uma discussão acerca da prerrogativa divina sobre a criação. Lembremos que é exatamente uma usurpação dessa prerrogativa que faz cair Lúcifer. O Demônio está fadado a atuar mediante a corrupção da ordem. Esse é seu único poder e seu ardil, já que todo princípio de criação, tendo origem Divina, lhe é vetado. A misoginia daquele texto está intimamente relacionada a um investimento civilizador no ato de criação e de procriação. Ora, o que aqui está em discussão é em que medida a associação entre mulher e fecundidade, entre mulher e natureza, não deve estar subordinada ao controle masculino e civilizador. De um lado, temos o poder, o direito de um deus capaz de propiciar a concepção mesmo na ausência do ato sexual, um deus capaz de criar o mundo ex nihilo; de outro, a resistência de mulheres que são levadas à fogueira por reivindicarem um acesso não subordinado à natureza e à procriação.

A solução desse impasse é fundamental na estruturação do poder patriarcal. Desde o Da Geração dos Animais, de Aristóteles, a possibilidade de tal insubordinação é encarada com preocupação. Ali aprendemos que se forças materiais, naturais, femininas prevalecem sobre forças formais, civilizadoras e masculinas, o processo de geração resultará na produção de corpos monstruosos. Não é fortuita a possibilidade de confluência entre helenismo e cristianismo neste ponto, patente na utilização do mito de Medusa como lastro das considerações religiosas de Kramer e Sprenger acerca do poder da visão. Digamos algo a esse respeito.

Para o grego, o monstruoso é hybris, desproporção, falha ou impossibilidade de civilização. Essa falha materializa-se tanto no corpo feminino quanto no corpo do bárbaro, demasiadamente frios para trafegarem sem o auxílio de roupas, demasiado frios para ocuparem espaços políticos de decisão. Sem o calor do princípio formal e civilizador masculino, a natureza se reproduz de modo metastático, monstruoso. A produção de monstros seria, portanto, o resultado de um tipo peculiar de acasalamento entre dois princípios fundamentais: de um lado, um princípio formal, uma causalidade eficiente, uma força masculina e quente; de outro a 
11 ARISTÓTELES, 1979, 729a. Em Alexandre e César: vidas comparadas, PLUTARCO, [s/d], p. 26 , refere-se ao calor do corpo de Alexandre como sendo uma evidência de sua virilidade. Mas não apenas isso, esse calor também é responsável pela fragrância de seu hálito e o cheiro de seu corpo. "Li, nas memórias de Aristoxeno, que sua pele era perfumada, exalando-lhe da boca e de todo o corpo um odor agradável, que lhe perfumava a roupa. Talvez isso se devesse ao calor de se temperamento, que era ardentíssimo; pois o bom odor é [...] o produto da cocção de humores, mediante o calor natural".

12 Jean-Pierre VERNANT, 1988, p. 393.

${ }^{13}$ Anne FAUSTO-STERLING, 1995.

${ }^{14}$ VERNANT, 1988, p. 46. matéria, o âmbito feminino, material e frio de geração do mundo biológico. ${ }^{11}$.

Sempre que a força e o calor do princípio formal não prevalecerem sobre o mundo material e feminino, teremos a produção de seres monstruosos. Em sua negatividade, o corpo monstruoso intima não apenas ao ver, mas ao ver a partir de uma lente ordenadora. Por oposição, essa experiência materializa um campo que corresponde à mirada civilizada. No caso do homem grego, essa mirada projeta um mundo gerado segundo princípios de ordem e de proporção. A educação civilizada [a Paidéia] significa a busca da proporção, da beleza das formas como princípios que devem se realizar no concreto desse homem. A natureza sem controle, o monstruoso, o bárbaro, devem ser sempre remetidos para além do mundo civilizado, masculino - para fora dos muros da polis.

Por esse motivo, o Minotauro precisa ser confinado. A górgona Medusa deve viver apartada dos homens, numa caverna, à espera de suas vítimas, ela própria vítima de sua pretensão desmedida ao comparar sua beleza à de Atena. Também se diz que sua cabeça vaga no limite entre o Hades e o mundo dos vivos. Como lembra Jean-Pierre Vernant, ${ }^{12}$ as górgonas (Medusa, Euríale e Esténea) são "instrumento de morte mágica", capazes de transformar pelo olhar o corpo quente (calor associado ao corpo masculino e civilizado) na pedra fria.

O monstro é um encontro com o Outro, com a Outra, com algo não facilmente passível de apropriação pela mirada civilizada. Não é à toa, portanto, que é para o viajante, para aqueles que perderam provisoriamente o seu lugar, como Alexandre, como Marco Pólo, como Colombo, que os monstros se revelam com mais frequência. Por isso mesmo, o Oriente é, para a imaginação ocidental, cenário de maravilhas terrenas, de perfeição incomparável ou inalcançável, mas também de monstros. A descoberta de terras povoadas ao sul do Equador produzirá um efeito semelhante na imaginação europeia. As primeiras representações dos povos das terras recém-descobertas eram bastante idílicas e, a partir do século XVII, essas representações idílicas começam a dar lugar ao selvagem monstruoso, ${ }^{13}$ desproporcional, hipersexualizado, canibal, amoral.

É comum que a cosmografia medieval confira um lugar próprio a cada criatura. Há um lugar adequado para o extraordinário, o fantástico, para o avesso. Para o pensamento medieval, "cada criatura é o seu próprio lugar". ${ }^{14}$ Disso decorre a necessidade lógica de uma divisão necessária do mundo em dois polos: existe um lugar para a perfeição, beleza e bondade. De fato, se é possível para Agostinho pensar num lugar para os monstros no projeto Divino, esse lugar é da 
15 Janis PALLISTER. In: PARÉ, 1983, p. xxvi.

16 PARÉ, 1983. alteridade, o lugar não civilizado diante do qual a beleza civilizada resplandece. Nesse contexto, retirar o próprio de seu lugar é agir de modo a contrariar os propósitos Divinos, ou procurar usurpar Seu poder de colocar cada coisa em seu próprio lugar. A circulação de bens, mercadorias, seres humanos que acompanha as grandes navegações põe em xeque esse fundamento do ideal medieval de civilização, ou, ao menos, age de modo a tornar problemática a cosmografia sobre a qual se constituem lugares civilizados em oposição a lugares bárbaros. Ao final da ldade Média, a lógica desse ideal de civilização entra em crise com a própria Revolução Comercial. Como seria possível aceitar a circulação de escravos negros em terras civilizadas? É preciso, portanto, que uma nova lógica se imponha.

\section{A circulação de corpos negros}

Na história da teratologia, Ambroise Paré é considerado um divisor de águas entre o pensamento medieval e a cultura renascentista. Janis Pallister, tradutor para o inglês do célebre Des monstres et prodiges, chegou a afirmar que o empirismo de Paré, no que concerne ao surgimento de monstruosidades, sua ênfase nas causas, no fenômeno da reprodução, torná-lo-iam um 'moderno' na Querela dos Antigos e Modernos - o que é um claro exagero. Paré é um homem dividido entre o compromisso de produzir manuais para seus pares cirurgiões em língua laica, de difundir, compartilhar conhecimento, e mesmo de definir critérios empíricos para qualificá-lo, e, por outro lado, de efetuar concessões à autoridade da tradição - quer essa autoridade venha de Aristóteles, Hipócrates, Plínio ou de um digno funcionário do Conde Fulano de Tal. A lógica que orienta a escrita de Monstros e prodígios é classificatória. Todo e qualquer monstro pertenceria a um de quatro domínios: terra, água, ar ou fogo. ${ }^{15}$

Quanto à sua causa, os monstros seriam de vários tipos, dentre os quais, destacamos: "determinados pela glória de Deus", "por sua cólera", "pela quantidade de sêmen" (demasiada ou escassa), "pela imaginação" (feminina, sempre), "postura indecente da mãe", "hereditariedade", pelo ardil de Demônios ou Diabos, "pelo artifício de mendigos". ${ }^{16}$ Este último caso merece uma nota especial, visto que, segundo uma lógica classificatória que estivesse mais próxima do conhecimento científico moderno, ele seria desprezado: ora, alguém que finge lepra ou ter três braços, ou seja, alguém que consegue esse efeito por fraude, dificilmente seria classificado como monstro, mas apenas como impostor. Paré não vê aqui uma contradição: trata-se de um impostor, mas ao mesmo tempo precisa ser classificado no rol dos monstros por aparecer diante de todos como tal. Ao 
17 Stuart EWEN e Elizabeth EWEN, 2006.

\footnotetext{
${ }^{18}$ EWEN; EWEN, 2006, p. 34.

${ }^{19}$ Ver a esse respeito o interessante artigo de Peter Mason (MASON, 2001), acerca dos diferentes regimes de troca com as quais as pinturas de Albert Eckhout de sujeitos brasileiros podem ser associadas.
}

nos depararmos com o princípio de organização de Monstros e prodígios, difícil não lembrar As palavras e as coisas, aquilo que Foucault julga como um passo na direção de uma episteme moderna, ou seja, a preocupação com a taxonomia, com a classificação dos seres a partir de suas similitudes e diferenças.

Com o declínio do feudalismo, diante da evidência da circulação de corpos considerados negros, monstruosos, corpos estrangeiros transformados em mercadoria, a vontade classificatória, ou seja, de poder perceber o lugar preciso a que cada coisa pertence, é reforçada. O desenvolvimento do capitalismo coloca as sociedades ocidentais diante de um dilema: já não poder operar confortavelmente a partir da noção cultural de que existiria um lugar próprio para todas as criaturas, dada a efetiva circulação de seres humanos no globo. Essa circulação implica a ideia de existência de um espaço vazio em que tudo possa ser trocado, intercambiado. Ao mesmo tempo, é necessário definir lugares próprios a partir dos quais o europeu, homem, branco, possa ser afirmado como centro do mundo civilizado. Em outras palavras, as pressões que decorrem desse tipo de circulação demandam formas de controle político bastante específicas.

Ewen e Ewen ${ }^{17}$ oferecem um relato interessante do modo como os 'gabinetes de curiosidades' são repensados ao final da ldade Média para dar conta dessa necessidade. Com o final das Cruzadas, a Europa parece ter sido invadida por relíquias sagradas trazidas da Terra Santa. Uma gota de leite da mãe do Cristo, pregos ou pedaços da cruz onde Jesus foi crucificado, o braço de um apóstolo, um pente usado por Maria Madalena etc., tornaram-se objeto da curiosidade e da devoção de fiéis. Junto com maravilhas naturais (cascos de tartaruga, chifres de unicórnios, ossos de animais préhistóricos), aquelas relíquias eram objetos sensíveis que alimentavam a fé cristã e, naturalmente, significavam o resgate de tesouros religiosos das mãos dos infiéis.

Em meados do século dezessete, a coleção e exibição de relíquias tinham migrado de suas raízes religiosas e apresentavam espécimes associados ao conhecimento científico e ao comércio global. Essa secularização de maravilhas começou, em alguma medida, durante o Renascimento, quando os aristocratas começaram a montar os primeiros museus de história natural. ${ }^{18}$

Passou a ser um sinal de distinção entre a aristocracia poder organizar tais coleções, alimentadas que eram pela empresa colonial. A posse do exótico era um signo de poder que mobilizou uma interessante dinâmica de dom e contradom entre príncipes europeus. 19 "Junto com animais, minerais 
${ }^{20}$ EWEN E EWEN, 2006, p. 26.

${ }^{21}$ FRIEDMAN, 2001, p. 105.

22 FRIEDMAN, 2001, p. 106.

${ }^{23}$ EWEN; EWEN, 2006, p. 60. e plantas exóticas, essas coleções também incluíam sequências bizarras de restos humanos". ${ }^{20}$ Reforcemos um ponto importante: tudo que não é civilizado deve ser considerado natural. Uma orquídea selvagem e os restos de nativos americanos, africanos ou asiáticos, guardadas certas distâncias que dão nuance ao gosto pela classificação, compõem parte de uma mesma totalidade.

Em A Mind of its Own. A Cultural History of the Penis, David Friedman nos conta da reação dos primeiros aventureiros ingleses ao pisar solo africano diante de uma natureza exuberante, dificilmente comparável aos padrões estéticos europeus. Mas foi a exibição de uma parte da vida selvagem local que chamou especialmente a atenção dos europeus: um certo Dr. Jacobus Surtor teve a oportunidade de encontrar nos sudaneses exemplos de uma máquina "aterrorizante", mais próxima do pênis de um "jumento" que de um "ser humano". O pênis do africano foi objeto de curiosidade não apenas de exploradores, mas da investigação "de cada uma das escolas de anatomia de Londres". ${ }^{21}$

O negro circula pela Europa como escravo, como mercadoria, e como possuidor de perigosas máquinas de reprodução. E essa circulação significa, por vezes, literalmente castração, ou seja, a circulação de membros amputados como curiosidade científica. A ciência emergente constrói canais através dos quais esses objetos de medo e admiração, de horror e de fascinação, circulariam de modo seguro: em jarras próprias à observação. Mas não apenas isso: essa ciência elabora um discurso que pavimenta esse trânsito. $O$ anatomista Edward D. Cope escreve, no século XIX, que "o cérebro maior do caucasiano prova sua superioridade intelectual e status civilizado, mas o maior pênis do negro prova sua inferioridade intelectual e selvageria inata". ${ }^{22}$ Esse tipo de discurso (ressentido) será repetido à exaustão no século XIX por cientistas como Gobineau, Lombroso, Galton.

Poder identificar, poder catalogar, localizar num espectro de gradações entre o bruto natural e o civilizado culto parece uma necessidade numa sociedade em que os laços sociais são constantemente refeitos pela força do capitalismo. Para o taxonomista do século XVIII, "cada forma de vida ocupava um lugar distinto dentro de um sistema inclusivo, [...] cada espécie corporificava um tipo ideal específico e poderia ser diferenciado por um conjunto único de características distinguíveis. Havia pouco espaço para ambiguidade". ${ }^{23}$ Do estudo da fisionomia de Lavater à anatomia comparada de Cuvier, a busca por estabelecer uma relação entre conformação física e essência cultural ou personalidade envolveu importantes nomes da ciência. E se podemos dizer que uma lógica de classificação por 
${ }^{24} \mathrm{No}$ livro As palavras e as coisas, Foucault propõe que, no que concerne à vida, a anatomia comparada de Cuvier opera uma passagem entre a episteme clássica e a episteme moderna. "Há uma história natural quando o Mesmo e o Outro pertencem a um só espaço; qualquer coisa como a biologia se torna possível quando uma unidade de plano começa a se desfazer e quando as diferenças começam a surgir sobre o fundo de uma identidade mais profunda e como que mais séria que ela" (FOUCAULT, 1966, p. 277). A própria ideia de uma "vida nua" constitui esse fundo e a ideia de diferença surge como algo diretamente associado à constituição de hierarquias: do sistema nervoso com relação ao digestivo, por certo, mas também do animal com relação à planta e do ser humano com relação aos animais. homologia - entre fisionomia e caráter - é um campo de transição entre formas pré-modernas e modernas de conhecimento científico, o desejo de reduzir personalidade e cultura a um substrato físico, passível de objetivação, já é um passo claro na direção da modernidade. Assim, se Lineu oferece um modelo de classificação em que a ordenação e organização dos reinos, classes e espécies vivas são hierarquicamente dispostas sob a primazia do Homo sapiens, seu discípulo Johann Friedrich Blumenbach irá mais longe ao propor uma hierarquia entre uma raça primordial (caucasiana) e quatro formas de degeneração deste modelo (etíope, mongoloide, americana e malasiana). Entre Lavater e Cuvier, ${ }^{24}$ Lineu e a classificação das espécies oferecem um modelo de hierarquia que será apropriado pelo discurso racial na biologia.

Mas para que essas espécies pudessem ser comparadas, classificadas e hierarquizadas, um poderoso comércio de mercadorias e de relíquias teve que transformar a Europa. Ordena-se aqui precisamente aquilo que se percebe como carente de ordem ou passível de comprometê-la. Acreditamos que essa é precisamente a lógica que torna o comovente caso de Sara Baartman importante de ser apreciado.

\section{A Vênus Hotentote: três discursos sobre o monstruoso}

Sara Baartman, mulher negra de cerca de $1,37 \mathrm{~m}$ de altura, saída das profundezas do que hoje corresponde ao território sul-africano, ficou conhecida como Vênus Hotentote e foi exibida em feiras, circos, hospitais e museus da Europa do início do século XIX até 1994, quando seus restos mortais foram devolvidos a seu povo, os Khoisan. A junção dessas duas palavras poderia parecer um oximoro, não fosse aquilo a que nos referimos anteriormente como a força ambígua do estereótipo. Temos aí, na verdade, dois estereótipos em um só. Por um lado, a imagem da Vênus, a deusa do amor e da beleza; por outro, o povo mais selvagem, mais animalesco, mais aparentado com os orangotangos que povoavam a imaginação dos europeus do século XIX.

Objeto do olhar dos europeus em parte devido às suas virtudes calipígias ou, em linguagem menos poética, ao que se conhece como esteatopigia ou hipertrofia das nádegas por acúmulo de gordura, Baartman é dupla e grotescamente ligada à imagem da Vênus. Uma das ideias implícitas nessa associação é a identificação de terras descobertas pelos europeus como femininas, prontas a serem penetradas, exploradas, desbravadas e civilizadas. A segunda é a referência irônica (e mesmo sarcástica) à 
${ }^{25}$ Cf. Bill LONG, 2007.

${ }^{26}$ HOLDEN apud LONG, 2007. Passa-se, então, a falar de "hotentotismo", ideia que serve de justificação às missões religiosas e outros projetos civilizatórios e exploratórios, conforme se pode depreender das palavras de um dos maiores poetas do romantismo inglês, Samuel Taylor Coleridge: "alguns hotentotes foram convertidos do hotentotismo por meio do trabalho piedoso da Sociedade Missionária" (COLERIDGE, 1850, p. 957).
Afrodite Kallipygus, ou Vênus Calipígia, a das belas nádegas, cuja representação mais famosa é o mármore romano adicionado ao Museu Real de Nápoles poucos anos antes da chegada de Baartman à Inglaterra.

O outro nome associado a ela, hotentote, foi utilizado pelos colonizadores holandeses da África do Sul desde o século XVII como uma espécie de onomatopeia que descrevia os sons de clique característicos de alguns dialetos africanos. "Hot-en-tot" significava "gago" e, segundo a definição do Oxford Dictionary, designa "alguém de cultura e intelecto inferior". ${ }^{25}$ Essa definição é compatível com a visão europeia predominante até o século XVIII e que classificava os povos de acordo com graus distintos de civilização, algo que muda substancialmente no século XIX com a introdução do conceito de raça. A classificação dos séculos XVII e XVIII está intimamente associada à ideia de caráter de um povo, e a incivilidade ou o barbarismo daqueles descritos como hotentotes aparece claramente nos relatos dos viajantes ingleses dos séculos XVII e XVIII: "Por meio de sua ausência de fé, de sua inconstância, mentira, engano, traição e preocupações infames com todo tipo de lubricidade, eles exercem sua vilania. ${ }^{26}$

É a partir dessas representações de uma Vênus hipersexualizada, por um lado, e de um povo que se encontrava na base da hierarquia civilizatória, por outro, que podemos compreender os olhares dirigidos a Baartman em sua chegada à Inglaterra, em 1810. Seu período inglês corresponde ao que chamaremos aqui de primeira mirada na Vênus, quando a politização do seu corpo apaga as diferenças específicas de seu povo à medida que ele é apropriado pelo movimento antiescravagista inglês. A segunda mirada, que corresponde ao período que passou em Paris, refere-se ao olhar clínico dos cientistas da época, notadamente o de Georges Cuvier, considerado o pai da anatomia comparada. Por fim, a terceira mirada corresponde à dos movimentos sociais contemporâneos, que elevaram Baartman à condição de ícone das lutas anticolonialistas e heroína nacional da África do Sul - constituindo-se em objeto de uma intensa negociação entre os governos de Nelson Mandela e de François Mitterand, numa querela política que durou cerca de sete anos, a fim de que seus restos mortais fossem retirados do Musée de L'Homme, em Paris, e devolvidos ao seu povo.

\section{A primeira mirada na Vênus}

Embora nos últimos anos Sara Baartman tenha se tornado objeto de um grande número de artigos, romances e até documentários, sabe-se pouco sobre ela. A maioria das informações vem de artigos de jornal, de relatórios 
${ }^{27}$ BLACKLEDGE, 2003.

${ }^{28}$ FAUSTO-STERLING, 1995.

${ }^{29}$ Stephen GOULD, 2004, p. 272.

${ }^{30}$ Sadiah QURESHI, 2004, p. 235.

31 Percival KIRBY apud FAUSTOSTERLING, 1995, p. 29.

32 QURESHI, 2004.

${ }^{33}$ GOULD, 2004. científicos daqueles que a examinaram e de autos de um processo no qual esteve envolvida. As fontes diferem, por exemplo, em relação a sua data de nascimento e de sua morte. Diversos autores afirmam que ela nasceu em 1789 ou 1790 e que tinha entre 19 e 20 quando chegou à Inglaterra, em 1810. ${ }^{27}$ Outros, entre eles Cuvier, afirmam que ela tinha 28 anos quando faleceu em Paris, no final de 1815, enquanto a inscrição da caixa em que ela foi exibida no Musée de L'Homme informa que ela morreu aos 38 anos. ${ }^{28} \mathrm{O}$ que é certo, no entanto, é que chegou à Inglaterra em 1810, trazida por Alexander Dunlop, médico de um navio inglês que exportava espécimes da fauna, flora e nativos das colônias inglesas. Como Baartman chegou às mãos de Dunlop já não é tão certo.

Acredita-se que Dunlop a tenha comprado de Peter Cezar, um fazendeiro holandês que habitava próximo à Cidade do Cabo e não que ela tenha acompanhado Dunlop por livre e espontânea vontade. Seu status de escrava não é comprovado, mas foi da família Cezar que recebeu o seu nome, cujo diminutivo Saartjie, "ou pequena Sara em africâner", ${ }^{29}$ era um tratamento comum dispensado aos escravos e aos negros em geral, ao atribuir a eles o status de crianças. ${ }^{30}$

Nessa época, a nação hotentote estava oficialmente sob a guarda do governador britânico no Cabo da Boa Esperança "em razão do seu estado de imbecilidade geral", ${ }^{31}$ e suspeita-se de que Dunlop tenha se aproveitado de seu status como médico para conseguir autorização para sua exportação, da mesma forma que conseguia autorização para a comercialização de plantas e animais exóticos. ${ }^{32}$ Foi Hendrick Cezar, irmão de Peter Cezar, que conseguiu a documentação necessária para levá-la à Inglaterra. ${ }^{33} \mathrm{Com}$ a autorização em mãos, Dunlop leva Baartman à Inglaterra, juntamente com um couro de girafa. Ao chegar lá, oferece-a a um colecionador de produtos exóticos trazidos das colônias e, mais tarde, proprietário do Salão Egípcio, um museu localizado em Londres, que recusa a oferta. Baartman é então oferecida ao mesmo Hendrick Cezar que teria conseguido a autorização para levá-la para a Europa.

Alguns autores sugerem ter sido ele o responsável pela exibição pública de Baartman no próprio Salão Egípcio, onde o público poderia observá-la em grupos, de no mínimo 12 pessoas, ao preço de dois xelins por cabeça. A propaganda para o show enfatizava ainda que ela possuía formas grandemente admiradas por seus compatriotas e que sua roupa, muito apertada e no tom de sua pele, dava a impressão de que estava nua. Além disso, usava contas e penas de avestruz, elementos associados à sua ancestralidade africana, e, ocasionalmente, tocava um instrumento de uma 
${ }^{34}$ QURESHI, 2004, p. 236-37.

${ }^{35}$ FAUSTO-STERLING, 1995.

${ }^{36}$ FAUSTO-STERLING, 1995.

${ }^{37}$ QURESHI, 2004, p. 240-41. corda só. ${ }^{34} \mathrm{O}$ show estabelecia uma relação íntima e direta entre as noções da fêmea selvagem, por um lado, e de uma sexualidade perigosa e incontrolável, por outro. No início de sua apresentação, ela era conduzida por um treinador ou carcereiro que lhe ordenava sair e entrar em sua jaula, sentarse e levantar-se. A imagem de sua natureza selvagem e perigosa era ainda enfatizada à medida que Baartman balançava-se para frente e para trás em sua jaula, como um animal selvagem. ${ }^{35}$

Inicialmente, a exibição de Baartman não apresentaria nada de excepcional se considerarmos que a exibição de curiosidades humanas, objetos e animais exóticos era comum na Inglaterra. Anões, gigantes, mulheres barbadas, negros, indígenas, porcos falantes, animais monstruosos e raros compunham a estranha fauna dos conhecidos shows de aberrações (ou freak shows) - zoológicos humanos e animais, museus, feiras e circos faziam parte das possibilidades de entretenimento oferecidas nas cidades europeias. Alguns desses espetáculos eram itinerantes, constituindo-se em um dos principais veículos para a criação de visões específicas acerca de um mundo não europeu, não civilizado. ${ }^{36}$ Ainda assim, a exibição de Baartman foi especial. Parte de seu sucesso parece dever-se ao fato de que era mulher.

Embora Londres tivesse uma população negra significava para a época (estima-se em cerca de 20.000 o número de negros residentes em Londres, em 1764, e o censo de 1801 registra uma população total de 958.863 habitantes naquela cidade), a grande maioria dos ex-escravos eram homens. ${ }^{37}$ Mulheres, especialmente Khoisans, não eram comuns. Mas isso não explica a história toda. De fato, Baartman só se torna um sucesso de público quando uma questão política vem à tona e seu caso passa a ser percebido a partir de uma outra perspectiva: a do movimento abolicionista inglês. A escravidão foi abolida na Inglaterra em 1807, isto é, meros três anos antes da chegada de Baartman, tendo perdurado até 1833 nas colônias inglesas. Os anos que se seguiram à abolição na Inglaterra correspondem ao período em que o movimento antiescravagista estava reunindo forças para estender a abolição para as colônias e uma de suas estratégias políticas consistia em criar uma imagem unitária do negro que apagava as diferenças entre os diversos povos. Certamente Baartman era diferente: sua caracterização como hotentote, sua estatura, sua esteatopigia, a forma de sua genitália (objeto de debate desde o século XVII) apontavam para características específicas que não eram compartilhadas pelos ex-escravos que habitavam as cidades inglesas. Não é, portanto, evidente que ela pudesse ser identificada como membro de um mesmo grupo (negros) apenas a partir da cor de sua pele. 
${ }^{38}$ Cf. GOULD, 2004, p. 273.

${ }^{39}$ QURESHI, 2004, p 238.

40 GOULD, 2004; FAUSTOSTERLING, 1995; QURESHI, 2004.
Um membro de uma das diversas organizações abolicionistas que atuavam na Inglaterra do início do século XIX, a Associação Africana, assistiu a uma das performances de Baartman, deixando claro seu caráter desumano: "a hotentote foi apresentada como um animal selvagem, e foi-lhe ordenado que andasse para trás e para diante, e que saísse e entrasse na jaula, mais como um urso treinado do que como um ser humano". ${ }^{38}$ Foi a partir dessa perspectiva que, em 12 de outubro de 1810, o jornal inglês Morning Chronicle publicou uma carta de denúncia enviada por "um cidadão inglês" que acreditava que a exibição de Baartman era "contrária a todo princípio de moralidade e ordem" na medida em que relacionava "ofensa à decência pública com a mais terrível das situações, a escravidão". A resposta de Hendrick Cezar veio na forma de duas cartas, nas quais enfatizava que ela tinha o mesmo direito de se exibir para ganhar a vida que um "gigante irlandês ou um anão". ${ }^{39} \mathrm{O}$ caso acabou na justiça e os abolicionistas, que se autoproclamaram protetores de Baartman, argumentaram no tribunal que a exibição era indecente e que ela estava presa contra sua vontade. Juntamente com a Associação Africana, os abolicionistas tentaram repatriar Baartman para sua terra natal. Questionada em holandês perante o tribunal, ela afirmou que não sofria abuso sexual, que foi para Londres por livre e espontânea vontade, que compreendia perfeitamente bem que haviam lhe prometido metade dos lucros e que tinha até dois negrinhos para servi-la, mas que gostaria de roupas mais quentes. Ao final, a corte decidiu em favor de Hendrick Cezar quando este apresentou um contrato (possivelmente forjado) entre Baartman e Alexander Dunlop. ${ }^{40}$

Assim, o show continuou e foi exibido por outras cidades inglesas e irlandesas até cerca de 1814, quando Baartman deixou de ser uma novidade e foi para Paris, onde passou a ser exibida pelo criador de animais S. Réaux. Sua temporada em Paris, que dura até sua morte em 1815, constitui o que denominamos de segunda mirada na Vênus.

\section{A segunda mirada na Vênus}

Sara Baartman começa a ser exibida em Paris em 1814 pelo treinador de ursos e de macacos Sieur Réaux. Lá, suscita a mesma curiosidade que na Inglaterra e sua popularidade chama a atenção de Étienne Geoffroy Saint-Hilaire, pai da teratologia moderna. Antes de desenvolver seus trabalhos em teratologia, Saint-Hilaire foi mentor e colega de Georges Cuvier. Ambos trabalhavam no Museu de História Natural de Paris e a chegada da Vênus na cidade fez com que ele (então administrador do museu) escrevesse uma carta ao chefe da polícia daquela cidade, relatando o desejo dos naturalistas 
41 SAINT-HILAIRE apud Jean Le GARREC, 2002, p. 7.

${ }^{42}$ RHRYNE apud John BAKER, 1974.

43 BAKER, 1974.

${ }^{44}$ SAINT-HILLAIRE apud LE GARREC, 2002 , p. 7.

${ }^{45}$ SAINT-HILLAIRE apud LE GARREC, 2002, p. 7. de "se beneficiarem da circunstância (oferecida) pela presença, em Paris, de uma fêmea bosquímana que pode fornecer, com mais precisão do que jamais foi feito até hoje, as características distintivas desta raça curiosa." 41

Foi assim que, no início de abril de 1815, a nudez de Baartman foi exposta ao olhar de cientistas e artistas no Jardin du Roi. Nessa exibição, ela posou para as ilustrações que compõem parte das imagens do livro de Cuvier e Saint-Hilaire, editado alguns anos mais tarde, História Natural dos Mamíferos. Essas imagens representam um olhar completamente diferente dirigido ao corpo de Baartman. Ao contrário das caricaturas relativas à sua estadia na Inglaterra, as imagens que ilustram a História Natural dos Mamíferos representam-na como uma espécie natural, dentre inúmeras outras, especialmente de macacos.

Um dos principais objetos de interesse anatômico em relação a Baartman era sua esteatopigia e sua genitália. Diversos relatos de viajantes, desde o século XVII, afirmavam que os homens Khoisan tinham apenas um testículo e as mulheres, um "avental", ou uma saliência genital cuja forma era objeto de muita especulação. Em uma das primeiras descrições por escrito da genitália dessas mulheres, em um livro publicado em 1686, Wilhelm ten Rhryne, médico da Companhia das índias Ocidentais, afirmou que "elas têm esta peculiaridade em relação a outras raças, a maioria delas possui apêndices em forma de dedos, sempre duplos, pendurados de suas partes privadas; trata-se, evidentemente, de nymphae" (a palavra latina para pequenos lábios). ${ }^{42}$ Uma outra descrição, de cerca de 1708, refere-se à genitália das mulheres Khoisan como uma dobra de pele semicircular que pende da parte inferior do abdômen, cobrindo a genitália externa. ${ }^{43}$ Foi essa descrição que deu origem ao nome "avental hotentote". Outros relatos de viajantes, ligando mais diretamente as características anatômicas dos Khoisan aos animais, questionavam-se a respeito da relação entre o "avental hotentote" e a cauda dos animais.

A aproximação desta com os animais é evidente na descrição de sua face que, segundo Saint-Hillaire, comporta a "base de um focinho ainda mais pronunciada que a do orangotango vermelho que habita as maiores ilhas do Oceano Índico". ${ }^{44} \mathrm{O}$ relatório afirma, ainda, que "o tamanho extraordinário de suas nádegas" Ihe inspira uma comparação entre as fêmeas dos macacos mandril na época do cio. ${ }^{45}$ Informado da morte de Baartman pela polícia, Cuvier solicita uma permissão especial para dissecar seu cadáver. A permissão decorria do fato de que, segundo a lei francesa, apenas a Faculdade de Medicina e o hospital de la Pieté poderiam executar autópsias. A fim de levá-la para o laboratório de anatomia do museu, Saint-Hillaire redige uma carta ao prefeito 
${ }^{46}$ LE GARREC, 2002, p. 7.

${ }^{47}$ CUVIER apud LE GARREC, 2002 , p. 16.

${ }^{48}$ CUVIER apud LE GARREC, 2002 , p. 16.

${ }^{49}$ FAUSTO-STERLING, 1995, p. 26.

${ }^{50}$ FAUSTO-STERLING, 1995. de Paris, solicitando a doação de seu corpo para que "ele possa auxiliar no progresso do conhecimento humano". ${ }^{46}$

A dissecação do cadáver, efetuada por Cuvier, foi precedida pela moldagem do corpo em gesso e seguida da extração de seu cérebro e de sua genitália, que foram preservados em formol e exibidos no Musée de l'Homme até 1974, juntamente com seu esqueleto. O relatório da dissecação, produzido por Cuvier, objeto de uma conferência na Academia de Medicina em 1817, chegava a conclusões semelhantes às de Saint-Hillaire e às dele próprio, quando a observaram meses antes no Jardin du Roi. Ecoando as palavras de Saint-Hillaire, Cuvier ${ }^{47}$ afirma que "seus movimentos tinham qualquer coisa de brusco e de caprichoso, o que lembrava o movimento dos símios. Ela tinha, sobretudo, uma maneira de projetar os lábios para frente que parecia com aquela que observamos no orangotango". Assim como Saint Hillaire, ele também faz referência à "enorme protuberância de suas nádegas e à aparência brutal de sua figura". ${ }^{48}$

O relatório da dissecação de Baartman apontava de forma inequívoca para uma concepção cientificista de raça, com base em um sistema taxonômico moderno. Como afirma Anne Fausto-Sterling, ${ }^{49}$ as crenças de Cuvier sobre as diferenças humanas espelham a transição de uma ênfase de diferenças em graus de civilização para a construção científica de raça, e seu trabalho no corpo de Sara Baartman "incorpora as contradições que esta transição inevitavelmente gera". Antes de investigarmos o conteúdo de seu relatório, algumas palavras sobre a noção de raça.

Até o século XVIII, a ideia de raças biológicas distintas permaneceu subdesenvolvida. Muitos dos que utilizavam esse termo não concebiam a diversidade humana em termos hereditários ou estritamente físicos, ${ }^{50}$ mas como uma mistura de elementos cuja base repousava sobre as crenças do senso comum acerca da inferioridade dos povos não europeus. Mesmo no século XVIII, naquilo que Stephen Jay Gould chama de "primeira definição formal das raças humanas", segundo os termos taxonômicos modernos,

Lineu mesclou traços do caráter com anatomia (Systema naturae, 1758). O Homo sapiens afer (o negro africano), afirmava ele, é 'comandado pelo capricho'; - Homo sapiens europaeus é 'comandado pelos costumes'. Sobre as mulheres africanas, escreveu ele: Feminis sine pudoris; mammae lactantes prolixae mulheres sem pudor, seios que segregam leite em profusão. Os homens, acrescentava, são indolentes e untam-se com sebo. ${ }^{51}$

A tradução de sine pudoris como "sem pudor" é depois corrigida pelo próprio Gould em uma obra posterior: ${ }^{52}$ o termo

52 GOULD, 2004. 
${ }^{53}$ BLACKLEDGE, 2003, p. 141.

${ }^{54}$ FAUSTO-STERLING, 1995, p. 27.

55 GOULD, 2003. que Lineu teria usado seria sinus pudoris (cortina do pudor) e não sine pudoris (sem pudor). A cortina do pudor refere-se justamente ao "avental hotentote" que tanto fascinou os viajantes europeus e os naturalistas daquele período, dentre eles, Georges Cuvier, que, em seu relatório de 16 páginas sobre Sara Baartman, dedica nada menos que nove à descrição de sua genitália. ${ }^{53}$ Diferentemente do que ocorria com os homens (brancos), que eram diferenciados de outros primatas por meio de características como a linguagem, a razão, a cultura etc., não apenas Cuvier, mas diversos cientistas da época se utilizavam de características anatômicas sexuais, as mais variadas, para distinguir as mulheres dos animais: "a forma dos seios, a presença do hímen, a estrutura do canal vaginal e a localização da abertura uretral". ${ }^{54} \mathrm{O}$ interesse de Cuvier em Sara Baartman é, portanto, inestimável: além de mulher, era negra, o que a tornava um objeto privilegiado de investigação científica, já que estava duplamente ligada à natureza, e duplamente distante da cultura.

A apresentação da genitália de Baartman no relatório de Cuvier é longamente precedida de sua identificação em termos raciais, pois é esta identificação que permitiria sustentar sua tese acerca da origem comum dos seres humanos, uma posição conhecida como monogenismo. "Permitiria" porque, ao contrário do que intentava, Cuvier acaba por se enrolar numa série de contradições que expõem a fragilidade de sua posição. Como argumenta Gould, ${ }^{55}$ as justificativas desse período para a hierarquização racial assumiam duas formas principais: um argumento brando, defendido pelos monogenistas, e um argumento mais duro, defendido pelos poligenistas. Os primeiros, ao misturar religião, senso comum e ciência, argumentavam que todos os povos descendem de Adão e Eva, isto é, de uma origem comum. As raças humanas seriam produto da degeneração da perfeição do paraíso e a menor degeneração teria ocorrido com a raça branca e, a maior, com os negros. Os poligenistas, por seu turno, rechaçavam a versão bíblica, considerando-a uma mera alegoria, e defendiam que as raças humanas eram espécies distintas e descendiam de mais de um Adão. Essa visão, é claro, era estritamente compatível com a escravidão, um dos temas de interesse de monogenistas e poligenistas, mas não era facilmente defensável. De acordo com a definição biológica, o que caracterizaria uma espécie era a possibilidade de cruzamento e da geração de descendentes férteis, o que, claro, era possível entre negros e brancos. Os monogenistas detinham, portanto, a vantagem no debate, embora isso não os impedisse de elaborar argumentos extremamente criativos a fim de tentar justificar a superioridade da raça branca.

Embora Cuvier defendesse a origem comum dos seres humanos e fosse um opositor ferrenho da escravidão, sua 
${ }^{56}$ FAUSTO-STERLING, 1995, p. 36.

57 FAUSTO-STERLING, 1995, p. 36. análise do corpo de Baartman revela uma insistência absurda em tentar localizá-la o mais próximo possível dos símios, distanciando-a da humanidade. Um dos recursos que ele utilizou para isso foi negar seu status de hotentote e caracterizá-la como bosquímana, uma raça que vivia nas profundezas da África, ainda mais profunda que os hotentotes. Mas o fato é que, embora não acreditasse na ideia de evolução, ao caracterizar Baartman como bosquímana, Cuvier acaba por caracterizá-la como o elo perdido entre os seres humanos e os macacos. Diferentemente dos hotentotes, os bosquímanos seriam inteiramente selvagens, pois sua estrutura social havia chegado a tal grau de degeneração que "eles não conhecem nem o governo, nem a propriedade; raramente se organizavam em famílias, mas apenas quando sua paixão os ditava... Eles subsistiam apenas pelo roubo e pela caça, viviam apenas em cavernas e cobriam seus corpos com os animais que haviam matado". 56

Para Fausto-Sterling, ${ }^{57}$ a relação que Cuvier estabelece entre a descrição da genitália de Baartman e as profundezas da África aparece claramente na sua reclamação de que ela havia escondido seu "avental" entre as pernas, ou em algum lugar mais profundo, durante sua exibição no Jardin du Roi. Ele teria ainda relacionado a existência de um povo primitivo e supostamente oculto com um primitivismo animal que os tornaria mais próximos dos orangotangos do que dos negros. São as relações entre genitálias estranhas, colônias distantes e animais exóticos que constituem o objeto de crítica dos movimentos sociais do final do século XX, atentos não apenas às relações entre a ciência e o colonialismo, mas às noções de raça e gênero que Ihes dão sustentação. Essas críticas voltam, mais uma vez, o olhar contemporâneo para Sara Baartman, constituindo o que caracterizamos de terceira mirada na Vênus.

\section{A terceira mirada na Vênus}

Depois de quase 200 anos submetida ao olhar degradante dos europeus, Baartman efetua a viagem de volta à sua terra natal, agora caracterizada como um sujeito inteiramente distinto dos anteriores: em lugar da mulher monstro, a heroína nacional que encarna uma série de valores politicamente corretos e, de um determinado ponto de vista, tão arbitrários quanto os que a condenaram a uma vida subumana. Os horrores decorrentes de diversas políicas cientificamente embasadas durante o século XX serviram de combustível para questionar noções como objetividade, neutralidade e verdade, associadas à ciência. Tais indagações injetaram força nos movimentos sociais que 
${ }^{58}$ QURESHI, 2004, p. 246.

${ }^{59}$ LE GARREC, 2002, p. 11-12.

${ }^{60}$ RICHERT, 2002, p. 6.

${ }^{61}$ LE GARREC, 2002, p. 9. passam a reclamar uma nova identidade para Baartman. Talvez o primeiro movimento social que serviu de denúncia à exposição e reificação do corpo de Baartman tenha sido o movimento feminista. No início dos anos de 1970, feministas francesas alegaram que sua exibição consistia em uma representação degradante das mulheres. O movimento iniciado por elas levou à remoção de seu esqueleto, em 1974, e do molde em gesso do seu corpo, em 1976, para os porões do Musée de l'Homme.$^{58} \mathrm{~A}$ partir de então, essas peças foram exibidas em uma única exposição, em 1994, intitulada $A$ Escultura Etnográfica no Século XIX: da Vênus Hotentote à La Tehura de Gauguin, primeiro no Musée d'Orsay, depois em Arles. ${ }^{59}$ (Os jarros contendo seu cérebro e sua genitália, ao que tudo indica, permaneceram guardados (escondidos?) no porão do museu.

No ano da última exposição pública de Baartman, os descendentes dos Khoisan, organizados num movimento chamado "conferência nacional Griqua", deram início a uma campanha pública de repatriação de seus restos mortais. Com o fim do regime do Apartheid, em 1994, estabeleceu-se a necessidade da criação, no plano simbólico, de elementos que pudessem representar uma nova identidade nacional. Isso incluiu não apenas uma releitura da história do país por meio de uma reforma do ensino, mas também, e talvez principalmente, a criação de novos heróis nacionais que resumissem, de alguma forma, qualidades consideradas importantes. É aí que ganham força os movimentos de grupos étnicos minoritários, amplamente apoiados pelo movimento estudantil, pelo movimento feminista, pela mídia e pelo governo sul-africano. De fato, pouco depois da eleição de Nelson Mandela, em uma visita oficial do presidente francês, François Mitterrand, o presidente recém-eleito transmitiu o desejo do povo sul-africano de reaver os restos mortais de Baartman..$^{60} \mathrm{~A}$ posição do governo sul-africano era a de que o retorno da "Vênus Hotentote" era nada menos que um símbolo de "descolonização psicológica". ${ }^{61} \mathrm{E}$ foi assim que Baartman, identificada como subumana pela ciência europeia do século XIX, tornou-se heroína nacional da África do Sul.

As suas linguagens, com cliques complexos, foram certa vez desprezadas como uma mixórdia gutural de sons animalescos. São agora admiradas pela sua complexidade e sutileza de expressão. Cuvier estigmatizara o estilo de vida de caça e extrativismo dos San (boximanes) tradicionais como a degradação suprema de um povo estúpido e indolente demais para se dedicar à agricultura ou à criação de gado. As mesmas pessoas hoje se tornaram modelos de retidão para os modernos militantes ecologistas devido 
62 GOULD, 2004, p. 279.

${ }^{63}$ Art. L. 52, Code du Domaine de l'Etat apud RICHERT, 2002, p. 18.

${ }^{64}$ RICHERT, 2002.

${ }^{65}$ LE GARREC, 2002.

${ }^{66}$ RICHERT, 2002, p. 8.

67 LANGANAY apud RICHERT, 2002, p. 11. à sua abordagem compreensiva, não exploratória e equilibrada dos recursos naturais. ${ }^{62}$

Apesar disso, foram necessários oito anos de negociação intensa para que Baartman pudesse ser devolvida a seu povo e cremada segundo os rituais Khoisan. A repatriação, símbolo do processo de descolonização, esbarrou na lei francesa, que afirma que "os bens do domínio público são inalienáveis e imprescritíveis." 63 Baartman, ou seus restos mortais, era, oficialmente, parte do patrimônio público francês e devolvê-la à África do Sul representaria um precedente importante no sentido de requisições, por parte de outras excolônias, de devolução do patrimônio roubado durante a colonização. Crescentemente pressionado pela opinião pública internacional, o governo da França não teve outro remédio senão ceder. Seria necessária uma modificação na lei, mas de forma tal que isso não representasse riscos aos museus da Europa e seu patrimônio. Uma análise dos relatórios do projeto de lei apresentado ao Senado francês ${ }^{64}$ e de sua aprovação ${ }^{65}$ deixam claras as preocupações do governo da França nesse sentido.

Ocorre que, em 1994, a "lei bioética" foi sancionada e incluída no código civil. Essa lei, redigida em termos bastante genéricos, tinha por objetivo interditar atentados à dignidade humana, "notadamente por meio do comércio de órgãos ou de elementos do corpo humano retirados de seres vivos ou de cadáveres". ${ }^{66}$ Isso gerou um problema considerável, pois, se a lei se aplica a coleções científicas, como as coleções etnográficas dos museus, os restos de Baartman não poderiam ser considerados como patrimônio, nem privado, nem do Estado, e o museu não poderia ser considerado seu guardião legal. Fez-se necessário, portanto, esclarecer em que medida a lei poderia ser aplicada aos restos humanos conservados nas coleções científicas. Isso, por sua vez, levou à necessidade de caracterizar a natureza do interesse científico suscitado.

Este foi talvez o mais interessante argumento desenvolvido pelos franceses, revelando toda a ambiguidade e ansiedade presentes no discurso civilizador por meio do olhar do monstro. A fim de não reproduzir os argumentos racialistas do século XIX, o relatório do projeto de lei faz referência à fala do então diretor do laboratório de antropologia biológica do Musée de l'Homme, o prof. Langanay. Segundo o referido professor, "o esqueleto de Saartjie Baartman 'não é nada mais do que o esqueleto de uma fêmea de pequena estatura' e qualifica de 'racista' a dissecação efetuada por Georges Cuvier". ${ }^{67}$ Por essa razão, e somado ao fato de que a ciência não poderia, mesmo por meio da genética, chegar a conclusões aceitáveis com base na análise de um único 
indivíduo, Baartman passa a ser também considerada como desprovida de interesse científico. O projeto de lei é, assim, aprovado, fazendo referência específica ao seu nome a fim de evitar que a lei seja aplicável a outros casos. Assim, ao proclamar Baartman como desprovida de interesse científico, o governo francês permite que seus restos mortais sejam enviados à África do Sul em maio de 2002 e cremados segundo rituais Khoisan.

\section{Cada coisa em seu lugar}

Conforme argumentamos no início de nossa exposição, a fim de que possa manter sua força, o discurso civilizador precisa estabelecer um jogo complexo de inclusão e exclusão de um/a Outro/a que funda sua identidade. Sara Baartman, ao longo das sucessivas miradas de que foi objeto, ilustra de forma especialmente interessante os movimentos desse jogo à medida que sua identidade é constituída pelo discurso civilizador. As condições materiais da construção de Baartman como um sujeito específico estavam intimamente atreladas ao processo de expansão capitalista que possibilitou a criação e a exibição de coleções de objetos, de animais e de seres humanos considerados exóticos. As cabines de curiosidades, os museus, as feiras, os circos e os zoológicos animais e humanos tornaram-se especialmente populares na Europa do século XVIII, abrindo o caminho para a criação de um outro monstruoso e perigoso, identificado, sobretudo, com os negros e as mulheres. Esse outro viria a representar o limite externo da humanidade, concebida em torno de ideias como razão, autocontrole, proporção, beleza, virilidade. Quando Baartman chega à Inglaterra, no início do século seguinte, é este Outro monstruoso que ela vem a encarnar de forma dupla: como mulher e como negra.

O nome com que se tornou conhecida, Vênus Hotentote, aponta para as ambiguidades presentes na construção de uma identidade a partir da tentativa de exclusão do que poderíamos qualificar de um alter ego monstruoso. Este duplo, assim como Mr. Hyde, que habitava as profundezas da mente do Dr. Jeckyll no romance de Stevenson, insistia em se manifestar sob a forma de fascínio, medo, riso e escárnio

${ }^{68}$ BADOU apud LE GARREC, 2002, p. 13. dirigidos à Vênus. Como afirma Gerard Badou, ${ }^{68}$ "[sua] sensualidade monstruosa tinha qualquer coisa de obscena, mas também de sagrada, que aprisionava o espectador nas profundezas de seu self. Este, atormentado por pulsões contraditórias, escapava por meio do riso e da piada". O riso e o escárnio de que Baartman foi alvo indicam a construção de um objeto que, ao encarnar tudo o que se considera negativo, monstruoso, aberrante, assegura a positividade, a normalidade de seu oposto. Mais do que isso, assegura a 
própria humanidade dos europeus, que passam a se constituir como o Homem universal.

Este outro negativo torna-se ainda mais enraizado no que chamamos de segunda mirada na Vênus. Ao retirar o argumento da esfera da tradição, especialmente via a incorporação do conceito de raça ao vocabulário científico, o que se tem é um ocultamento dos interesses e preconceitos sob o manto da objetividade e da neutralidade da ciência da época. Hoje, que temos a vantagem da perspectiva histórica, podemos perceber com mais clareza a dimensão ideológica da classificação racial elaborada por Cuvier. Suas tentativas de aproximar Baartman dos símios e distanciá-la da humanidade se chocam frontalmente com seus pressupostos monogenistas e o aproxima, contra suas próprias crenças (científicas), da ideia de evolução. A leitura que Cuvier faz do corpo de Baartman deixa especialmente visível a relação entre a produção de conhecimento científico e crenças mais gerais acerca da estrutura da sociedade, de sua hierarquia, de seus valores.

Mas é sob a pressão política dos movimentos sociais contemporâneos, numa espécie de retorno da mirada do monstro, que o discurso civilizador da ciência revela toda a ambiguidade que o fundamenta. Por um lado, a humanidade de Baartman é conferida quando, deixando de ser considerada mera espécime natural, passa a fazer parte do mundo da cultura por meio de sua cremação segundo os rituais de seu povo; por outro, é esse mesmo discurso que possibilita a proteção do patrimônio dos museus da Europa. $\mathrm{E}$, assim, a circulação de outros corpos continua garantindo que tudo permaneça em seu devido lugar. Como dizem os franceses, et plus ça change...

\section{Referências bibliográficas}

ARISTÓTELES. Generation of Animals. Cambridge: Harvard University Press, 1979.

BAKER, John. "The 'Hottentot Venus'”. In:__ . Race. Oxford: Oxford University Press, 1974. Disponível em: <http://www.heretical. com/miscella/baker4.html > Acesso em: 15 ago. 2009.

BHABHA, Homi. O Local da Cultura. Belo Horizonte: Ed. UFMG, 1998.

BLACKLEDGE, Catherine. The Story of V: Opening Pandora's Box. Londres: Weidenfeld; Nicolson, 2003.

COLERIDGE, Samuel Taylor. Essays on his own Times. Londres: William Pickering, 2003. v. III. Disponível em: <http:// books.google.com/books?id=EDECAAAAQAAJ\&pg=PA9 57\&lpg =PA957\&dq $=$ coleridge + some + hottentots + were $+\mathrm{C}$ onverted +from + their +hottentotism \&source $=$ bl\&ots $=p 6 \mathrm{mzsA}$ CNI1 \&sig=P4rByUdG1 bOrZnfCXFRSjvZGTOQ\&hl=pt-BR\&ei 
$=$ fxilSuu2GsS_tgfZztTnDA\&sa $=X \&$ oi $=$ book_result\&ct $=$ result\&r esnum $=6 \# v=$ onepage $\& q=\& f=$ false $>$. Acessoem: 15 ago 2009.

DEL PRIORE, Mary. Ao sul do corpo: condição feminina, maternidades e mentalidades no Brasil Colônia. Rio de Janeiro; Brasília: José Olympio; Ed. da UnB, 1993.

DELUMEAU, Jean. História do medo no Ocidente: 1300-1800, uma cidade sitiada. São Paulo: Companhia das Letras, 1999.

EWEN, Stuart, and EWEN, Elizabeth. Typecasting: On the Arts and Sciences of Human Inequality. New York: Seven Stories Press, 2006.

FAUSTO-STERLING, Anne. "Gender, Race and Nation: The Comparative Anatomy of 'Hottentot' Women in Europe, 18151817". In: TERRY, Jennifer, and URLA, Jacqueline (eds.). Deviant Bodies. Bloomington: Indiana University Press, 1995.

FOUCAULT, Michel. História da loucura. São Paulo: Perspectiva, 1987.

. Les mots et les choses. Paris: Gallimard, 1966.

FRIEDMAN, David. A Mind of Its Own: A Cultural History of the Penis. Nova York: The Free Press, 2001.

GOULD, Stephen Jay. A falsa medida do homem. São Paulo: Martins Fontes, 2003. 2004.

O sorriso do flamingo. São Paulo: Martins Fontes,

GUIRAND, Félix. Mythologie générale. In: (org.). Paris: Librairie Larousse, 1935.

JAY, Martin. Downcast Eyes: The Denigration of Vision in Twentieth-Century French Thought. Los Angeles: University of California Press, 1994.

KRAMER, Heinrich; SPRENGER, James. O martelo das feiticeiras: Malleus Maleficarum. Rio de Janeiro: Rosa dos Tempos, 1991.

LE GARREC, Jean. "Rapport fait au nom de la commission des affaires culturelles, familiales et sociales sur la proposition de loi, adoptée par le Sénat, relative à la restituition par la France de la dépouille mortelle de Saartjie Baartman à l'Afrique du Sud". Sénat, Assemblée Nationale, n. 3563. Disponível em: <http//:www.assemblee-nationale.fr/ rapports/r3563.asp >. Acesso em: 15 ago. 2009.

LONG, Bill. Who are/were the Hottentots? 2007. Disponível em: <http://www.drbilllong.com/CurrentEventsX/Hottentot. html > Acesso em: 15 ago. 2009.

MASON, Peter. "Troca e deslocamento nas pinturas de Albert Eckhout de sujeitos brasileiros". Estudos de Sociologia, v. 7, n. 1 e 2, p. 231-250, 2001.

MINOIS, George. História do riso e do escárnio. São Paulo: UNESP, 2003. 
PARÉ, Ambroise. On Monsters and Marvels. Chicago: The University of Chicago Press, 1983.

PLUTARCO. Alexandre e César: vidas comparadas. São Paulo: Escala, [s.d.].

QURESHI, Sadiah. "Displaying Sara Baartman, The 'Hottentot Venus'". History of Science, v. 42, n. 2, 2004. p. 233-257. Disponível em: <http://www.shpltd.co.uk/qureshibaartman.pdf $>$. Acesso em: 15 ago. 2009.

RICHERT, M. Philippe. "Rapport fait au nom de la commission des affaires culturelles sur la proposition de loi de $\mathrm{M}$. Nicolas About autorisant la restituition par la France de la dépouille mortelle de Saartjie Baartman, dite 'Vénus Hottentote' à l'Afrique du Sud". Sénat, session ordinaire de 2001-2002, n. 177, 2002. Disponível em: <http:// cubitus.senat.fr/rap/l01-177//01-177.html>. Acesso em: 15 ago. 2009.

SENNETT, Richard. Carne e pedra: o corpo e a cidade na civilização ocidental. Rio de Janeiro; São Paulo: Record, 2003.

VERNANT, Jean-Pierre. A morte nos olhos: a figuração do outro na Grécia antiga. Rio de Janeiro: Zahar, 1988.

[Recebido em agosto de 2009 e aceito para publicação em março de 2010]

\begin{abstract}
Women, Negroes, and Other Monsters: An Essay on Non-Civilized Bodies
Abstract: The Western dynamics of civilization implies a tense relationship between body and mind, culture and nature, civilization and barbarism. In the following essay we explore the construction of the last one of such dualism by investigating the spaces where certain bodies are defined as monstrous. We are particularly concerned with the constitution of a scientific vision of racial differences, its specificity in relation to the medieval perception of the place of alterity, its role in legitimizing the circulation of 'monstrous' bodies as commodities and its claim to disclose an objective hierarchy of races and gender. From Lavater to Curvier, the classification of species offers a hierarchical model that will be appropriated by race and gender discourses in biology. Within this context, there is one case of paradigmatic quality, 'The Hottentot Venus'. We argue that the political negotiation of Sara Baartman's ontological status, during the $19^{\text {th }}$ and $20^{\text {th }}$ centuries, represents just such effort to establish the borders of civility through the circulation and exclusion of uncivilized bodies.
\end{abstract}

Key words: Women; Black Bodies; Teratology; Science. 